\title{
EVALUATION OF SOME PHYSICAL AND MECHANICAL PROPERTIES OF CHITOSAN MODIFIED THERMOPLASTIC DENTURE BASE RESIN
}

\author{
Mahmoud Abdellah *, Mohamed Shokry Ali **, Ramy Abdallah Abdelrahim ***
}

\begin{abstract}
Objective: This study was aimed to evaluate the effect of incorporation of chitosan nanoparticles (Cs/NPs) on flexural strength, impact strength, fracture toughness as well as, water sorption and solubility of thermoplastic resin material. Materials and Methods: Cs/NPs (Nano-gate Company, Egypt) was incorporated into thermoplastic resin (Bre-flex, Bredenttm, Germany) with different concentration (1.5 wt., 5wt., and $7 \mathrm{wt} . \%)$. This study was divided into four main groups; unmodified "control group" and four modified groups according to the concentration of the incorporated Cs/NPs. Results: The results of this study revealed that; the incorporation of $\mathrm{Cs} / \mathrm{NPs}$ decrease the flexural strength, impact strength, and fracture toughness of thermoplastic resin. While, the water sorption and solubility of modified thermoplastic resin were increased. Conclusion: The incorporation of Cs/NPs into thermoplastic resin at different concentrations could adversely affects its flexural strength, impact strength, fracture toughness as well as its water sorption and solubility.
\end{abstract}

Key Words: Chitosan, Nanoparticles, Mechanical properties, physical properties, Thermoplastic resin.

\section{INTRODUCTION}

The development of acrylic resins represented a great step forward in dental practice ${ }^{(1)}$. Usage of thermoplastic resin in dentistry has a significant and continuous grown especially in the last years due to their superior characteristics ${ }^{(2,3)}$. The manufacturing technology of thermoplastic resin is an only physical reaction. It based on thermal plasticizing of the material with the possibility of injected the plasticized resin into a mold using only thermal processing. This injection-molded technology opens a new way to construct removable dentures prosthesis ${ }^{(3,4)}$.

Thermoplastic resins have numerous advantages over the conventional thermoset resin systems such as; lightweight, monomer free, metal-free, strong "almost unbreakable", durable as well as they did not warp or become brittle ${ }^{(5,6)}$. Also, they can be fabricated in a thinner section than conventional thermoplastic acrylic dentures, affording more convenience and comfort for the patient ${ }^{(6)}$.

Thermoplastic resins generally composed of long linear chains which are responsible for their flexibility in use. However, the hydrophilic nature of this thermoplastic resin will lead to their hydrolysis and eventually damage the polymer chains during long-term usage. Furthermore, the polymer chain breakdown can negatively affect the physical properties of the thermoplastic resin ${ }^{(7-9)}$. While, the acrylic resin composed of long, branched, or crosslinked polymer chains, so, the breaking of polymer chains gives less effect on its physical properties ${ }^{(7,8)}$.

The thin thermoplastic resin requires sufficient mechanical strength to withstand the stresses generated during the function ${ }^{(10)}$. In recent years, nanotechnology has shown significant

\footnotetext{
* Assistant lecturer of Dental Biomaterials, Faculty of Dentistry, Asyut, Al-Azhar University.

** Professor and head of department of Dental Biomaterials, Faculty of Dentistry, Cairo, Boys, Al-Azhar University. *** Assistant Professor of Dental Biomaterials, Faculty of Dentistry, Cairo, Boys, Al-Azhar University
} 
attractiveness for the preparation of polymeric materials for prosthodontic with improved physical and mechanical properties ${ }^{(11)}$. Therefore, nanofillers have recently attracted the attention of the nanocomposite industry to overcome the drawbacks of the plastic industry ${ }^{(12,13)}$. The effect of nanoparticles on the physical and mechanical properties of the polymer depends on various factors including; particle size, polymer-particle interface, method of fabrication, and particle distribution in the polymer matrix ${ }^{(13,14)}$.

Chitosan (Cs) is a compound polymer of glucosamine and $\mathrm{N}$-acetyl glucosamine that obtained via partial deacetylation of acetyl glucosamine through alkaline deacetylation of chitin. Chitosan has several important biological properties such as; biodegradable, biocompatible, and bioactive. Also, it is a polycationic polymer which is a significant chemical property due to the presence of active amino and hydroxyl functional groups (11,15-18). Moreover, Chitosan also has a high resistance to heat due to its intramolecular hydrogen bonds ${ }^{(15,16)}$.

Therefore, the present study was carried out to demonstrate the influence of incorporation of chitosan nanoparticles (Cs/NPs) on some physical and mechanical properties of thermoplastic acrylic resin. The hypothesis was that the incorporation of Cs would improve the physical and mechanical properties of the thermoplastic resin.

\section{MATERIALS AND METHODS}

One type of acrylic resin; thermoplastic acrylic resins (iFlex, thermoplastic comfort systems, Inc., USA), and chitosan nanoparticles with different concentrations $(1.5,5$, and 7 wt.\%) were used in this study.

\section{Sample Grouping:}

Group I: unmodified thermoplastic resin (control group).

Group II: Thermoplastic resin modified with $1.5 \% \mathrm{Cs} / \mathrm{NPs}$.
Group III: Thermoplastic resin modified with $5 \% \mathrm{Cs} / \mathrm{NPs}$.

Group IV: Thermoplastic resin modified with $7 \% \mathrm{Cs} / \mathrm{NPs}$.

\section{Samples Preparation:}

The stainless-Steel die was milled from a metal blank according to the dimension of each test specimen. Then, the stainless-steel invested in a conventional dental flask to create a stone mold. For unmodified thermoplastic resin samples (control); thermoplastic resin samples were prepared after painting of stone mold with separating medium; via injected the thermoplastic resin using injection machine (Thermogen, Egyptian Engineering, Egypt) ${ }^{(3)}$.

For thermoplastic resin modified with $\mathrm{Cs} / \mathrm{NPs}$; The thermoplastic resin powder and Cs/NPs powder were pre-weighed with electronic analytical balance (Sartorius, Sartorius AG. Germany) to ensure a filler concentration of $1.5 \%, 5 \%$, and $7 \%$ by weight. Then, the modified resin powder was sonicated for 15 minutes in a sonicator (Elmasonic S $60 \mathrm{H}$; Germany) to obtain a more homogenous and equal distribution of Cs-NPs powder. Then; the newly formed thermoplastic/ Cs-NPs nanocomposites were injected using an injection machine in the previously prepared stone mold.

\section{Flexural Strength:}

The dimension of samples for this test was $65 \mathrm{~mm}$ length $\times 10 \mathrm{~mm}$ width $\times 2.5 \mathrm{~mm}$ thickness ${ }^{(19)}$. Each specimen was individually and horizontally mounted in a custom-made loading fixture on a computer-controlled material testing machine (Model LRX-plus; Lloyd Instruments Ltd., Fareham, UK) with a load cell of $5 \mathrm{KN}$. Then, the specimen was statically compression loaded until fracture at a crosshead speed of $5 \mathrm{~mm} /$ minute.

The maximum load exerted on the samples was recorded, and the flexural strength was calculated according to the following equation ${ }^{(20)}$ : 


\section{$F S=3 W L / 2 b d^{2}$}

Where; FS: flexural strength; W: load at fracture, $\mathrm{L}$ : span length of specimen (mm); b: width of the specimen $(\mathrm{mm})$; and $\mathrm{d}$ : thicknesses of the specimen $(\mathrm{mm})$.

\section{Impact Strength:}

The dimension of samples for this test was $75 \mathrm{~mm}$ length $\times 10 \mathrm{~mm}$ width $\times 10 \mathrm{~mm}$ thickness ${ }^{(21)}$. The impact strength test was performed using a Charpytype impact tester (Coesfeld, Pendulum Impact Tester, Dortmund, Germany). Impact strength (IS) was calculated using the following formula ${ }^{(22)}$ :

$$
I S=E / w t
$$

Where; E: is the energy required to break the specimen $(\mathrm{J}), \mathbf{w}$ : is the width $(\mathrm{mm})$, and $\mathbf{t}$ : is the thickness of the specimen $(\mathrm{mm})$.

\section{Fracture Toughness:}

The dimension of samples for this test was $65 \mathrm{~mm}$ length $\times 10 \mathrm{~mm}$ width $\times 2.5 \mathrm{~mm}$ thickness ${ }^{(21)}$. All samples were individually and horizontally mounted in a custom-made loading fixture on a computer-controlled material testing machine with a load cell of $5 \mathrm{KN}$. Then, the samples were statically compression loaded until fracture at a crosshead speed of $5 \mathrm{~mm} /$ minute.

The maximum load exerted on the samples was recorded, and the fracture toughness was calculated according to the following equation ${ }^{(23)}$ :

$$
K_{i c}=p c / b w^{I / 2} \times F_{(a / w)}
$$

Where; $K_{i c}:$ is fracture toughness (MPa.m ${ }^{1 / 2}$ ), $p c$ : is the maximum load $(\mathrm{KN})$ before the crack advance, $b$ : is specimen thickness $(\mathrm{cm}), w$ : is the width of the specimen $(\mathrm{cm}), a$ : is crack length $(\mathrm{cm})$ and $F$ : is calculated from the following equation:

$$
\begin{aligned}
& F_{(a / w)}= \\
& \frac{(2+a / w)\left(0.886+(a / w)-13.32\left(a^{2} / w^{2}\right)+\left(a^{3} / w^{3}\right)-5 .\left(6 a^{4}\right) / w^{4}\right)}{(1-a / w)^{3 / 2}}
\end{aligned}
$$

\section{Water Sorption and Solubility:}

The dimension of samples for this test was $50 \mathrm{~mm}$ diameter $\times 0.5 \mathrm{~mm}$ thickness ${ }^{(24)}$. The fully dried samples were weighed to obtain dry mass (M1).

All disk samples were transferred to separate glass vessel with $20 \mathrm{ml}$ of deionized water and stored in a $37^{\circ} \mathrm{C}$ incubator for 1 week. The deionized water was changed daily. After water storage, the samples were removed from the water, blot dried with an absorbent paper, waved in the air for 15 seconds, and weighed until the maximum wet mass (M2) was obtained.

Then, each disk was placed in a desiccator containing silica gel and weighed daily within 7 days to a constant dry mass (M3) to allow determination of the mass loss. The apparent water sorption and solubility were calculated for each disk using the following equations ${ }^{(25)}$ :

$$
\begin{gathered}
\text { Water sorption }=M 2-M 3 / V \\
\text { Solubility }=M 1-M 3 / V
\end{gathered}
$$

Where; M1: the mass of the specimen, in microgram $(\mu \mathrm{g})$, before immersion in water; $\mathrm{M} 2$ : the mass of the specimen, in $\mu \mathrm{g}$, after immersion in water; M3: the mass of the specimen, in $\mu \mathrm{g}$, after immersion and desiccation, $\mathrm{V}$ : the volume of the specimen in cubic millimeters $\left(\mathrm{mm}^{3}\right)$.

The volume of the specimen in $\left(\mathrm{mm}^{3}\right)$ was calculated using the following equation ${ }^{(26)}$ :

$$
V=\pi r^{2} \times h
$$

Where $\pi ; 3.14, \mathbf{r}$; the radius of the specimen in $(\mathrm{mm})$, and $\mathbf{h}$; thickness of specimen in ( $\mathrm{mm})$.

\section{Statistical Analysis}

All resulted data were collected, tabulated, and statistically analyzed using IBM ${ }^{\circledR}$ SPSS ${ }^{\circledR}$ statistics Version 25. Numerical data were described as mean and standard deviation. Data were compared using the ANOVA test. The level of significance will be set at $P<0.05$. 


\section{RESULTS}

\section{Flexural Strength:}

The results of this study revealed that; there were statistically significant differences among the tested unmodified and modified thermoplastic resin groups regarding the flexural strength $(p=0.008)$. It was found that the incorporation of chitosan nanoparticles significantly decreases the flexural strength of the thermoplastic resin at all concentrations. Also, it was found that the flexural strength of thermoplastic resin decreases proportionally with the increases in the amount of incorporated chitosan nanofillers as shown in (Table 1).

TABLE (1) Flexural strength results in (MPa) among tested groups.

\begin{tabular}{|c|c|c|}
\hline Variable & Mean $\pm \mathrm{SD}$ & \multirow{2}{*}{$p$-value } \\
\hline Group I & $48.291 \pm 1.9174^{\mathrm{A}}$ & \\
\cline { 1 - 2 } Group II & $42.388 \pm 3.0785^{\mathrm{B}}$ & \multirow{2}{*}{$0.008^{*}$} \\
\cline { 1 - 2 } Group III & $40.17 \pm 2.5029^{\mathrm{B}}$ & \\
\cline { 1 - 2 } Group IV & $39.703 \pm 1.7441^{\mathrm{B}}$ & \\
\hline
\end{tabular}

\section{Impact Strength:}

The results of the impact strength test exhibited a non-statistically significant difference $(p=0.185)$ between the modified and unmodified thermoplastic resin groups tested in this study. While, the mean values revealed that; the incorporation of chitosan nanoparticles decrease the impact strength of the thermoplastic resin and this decrease in values was in proportional with the increase of the amount of nanofillers as shown in (Table 2).

TABLE (2) Impact strength results in $\left(\mathrm{J} / \mathrm{mm}^{2}\right)$ among tested groups.

\begin{tabular}{|c|c|c|}
\hline Variable & Mean $\pm \mathrm{SD}$ & $p$-value \\
\hline Group I & $5.0385 \pm 1.2093$ & \\
\hline Group II & $4.4301 \pm 0.1740$ & \multirow{2}{*}{0.185} \\
\hline Group III & $4.047 \pm 0.2424$ & \\
\hline Group IV & $3.7209 \pm 0.1400$ & \\
\hline
\end{tabular}

\section{Fracture Toughness:}

The results of the fracture toughness test exhibited a statistically significant difference among the tested groups $(p=0.005)$. Unmodified thermoplastic resin samples exhibited the higher mean value, while, the mean values of modified thermoplastic resin samples decrease with the increase of the amount of incorporated chitosan nanoparticles as shown in (Table 3).

TABLE (3) Fracture strength results in (MPa. $\mathrm{m}^{1 / 2}$ ) among tested groups.

\begin{tabular}{|c|c|c|}
\hline Variable & Mean $\pm \mathrm{SD}$ & $p$-value \\
\hline Group I & $5.3389 \pm 1.2951^{\mathrm{A}}$ & \\
\cline { 1 - 2 } Group II & $4.3409 \pm 0.2478^{\mathrm{B}}$ & \multirow{2}{*}{$0.005^{*}$} \\
\cline { 1 - 2 } Group III & $3.9999 \pm 0.2164^{\mathrm{C}}$ & \\
\hline Group IV & $3.6998 \pm 0.1332^{\mathrm{C}}$ & \\
\hline
\end{tabular}

\section{Water Sorption:}

The results of water sorption revealed a statistically significant difference $(p=0.00000)$. Unmodified thermoplastic resin samples exhibited less water sorption followed by the thermoplastic resin samples modified by (1.5 wt., 7 wt., and 5 wt.\%) of chitosan nanoparticles respectively as shown in (Table 4). So, the incorporation of chitosan nanoparticles adversely affects the water sorption of thermoplastic resin.

TABLE (4) Water sorption (wt.\%) among tested groups.

\begin{tabular}{|c|c|c|}
\hline Variable & Mean $\pm \mathrm{SD}$ & $p$-value \\
\hline Group I & $0.0267 \pm 0.0089^{\mathrm{D}}$ & \\
\cline { 1 - 2 } Group II & $0.0503 \pm 0.0261^{\mathrm{C}}$ & \multirow{2}{*}{$0.00000^{*}$} \\
\hline Group III & $0.3214 \pm 0.0135^{\mathrm{A}}$ & \\
\hline Group IV & $0.1413 \pm 0.0192^{\mathrm{B}}$ & \\
\hline
\end{tabular}

\section{Water Solubility:}

For the water solubility test, it was found that; the thermoplastic resin samples modified with $1.5 \mathrm{wt} . \%$ 
chitosan nanoparticles exhibited the lower mean value of solubility, followed by the unmodified thermoplastic resin samples. While the thermoplastic resin modified with 5wt.\% chitosan nanoparticles exhibited the higher mean solubility value followed by thermoplastic resin modified with $7 \mathrm{wt} . \%$ chitosan nanoparticles. The difference between the effects of chitosan nanoparticles incorporation on the water solubility of thermoplastic resin samples (unmodified and modified) was not statistically significant $(\mathrm{P}>0.05)$ as shown in (Table 5).

TABLE (5) Water solubility (wt.\%) among tested groups.

\begin{tabular}{|c|c|c|}
\hline Variable & Mean \pm SD & $p$-value \\
\hline Group I & $0.0156 \pm 0.0042$ & \\
\hline Group II & $0.0134 \pm 0.0029$ & \multirow{2}{*}{0.172} \\
\hline Group III & $0.1370 \pm 0.1263$ & \\
\hline Group IV & $0.0825 \pm 0.0603$ & \\
\hline
\end{tabular}

\section{DISCUSSION}

Over the years, various materials have been used for the construction of resin denture bases. However, recently, new-generations of thermoplastic resins are more commonly used in the fabrication of denture bases as an alternative to the conventional PMMA resin material ${ }^{(27)}$. As, these materials have many advantages namely; flexible or semi-flexible structure, allergy-free, biocompatible with oral tissues, low density as well as higher esthetic properties ${ }^{(4)}$.

Daily use of denture can affect the mechanical and physical properties of the thermoplastic denture. Also, there is no way of controlling the stresses that transmitted in flexible dentures due to their flexibility ${ }^{(28)}$. So, many attempts have been made to improve the physical and mechanical properties of the acrylic resins such as incorporation reinforcing additives to the acrylic base resins by nanoparticles ${ }^{(10,12-14)}$.
The effects of the nanoparticles on the physicomechanical properties of nanocomposite are dependent on many variables but especially upon the particle's distribution in the polymer matrix, and relative crystalline or amorphous nature of the polymer matrix as well as the interaction between the filler at the matrix polymer/particle interface ${ }^{(15-18)}$.

Chitosan is a polycationic polymer that has active "amino" and "hydroxyl" functional groups (11,15-18). Moreover, Chitosan also has a high resistance to heat due to its intramolecular hydrogen bonds ${ }^{(15,16)}$, so it can use safely with the thermoplastic resin. Also, the percentage range of nanoparticles of (1.5, 5 , and $7 \mathrm{wt} . \%$ by weight) was selected in the present study because percentages above $7 \mathrm{wt} . \%$ was leads to massive color changes in the acrylic resin as mention in a previous study ${ }^{(29)}$.

There are several mechanical properties could be used to measure the strength of denture base materials. Flexural strength tests one of the most important tests that can exhibit the ability of resin materials to resist the functional masticatory forces, especially when used as denture bases ${ }^{(30)}$. Also, the impact strength test was commonly used to evaluate the denture base materials or to determine the effects of incorporated particles ${ }^{(31)}$. While fracture toughness is a fundamental property of the material to predict the resistance of the material to fracture when a crack is present ${ }^{(32)}$.

The effect of any additive on the physicomechanical properties of any resin materials should be evaluated to avoid all deleterious effects which may adversely affect their strength and reduce it to below standard level ${ }^{(33)}$.

The results of this study showed that the incorporation of Cs-NPs at all concentrations into thermoplastic acrylic resin decreases its flexural strength, impact strength, as well as its fracture toughness. These may be due to incomplete wetting of the chitosan nanofiller by the matrix, as a result of the absence of liquid monomer ${ }^{(34)}$. Moreover, the absence of monomers in the thermoplastic resin deprive the chitosan polymer of forming a covalent 
linkage with the linear chains of thermoplastic resin and only act as impurities ${ }^{(10,34)}$.

Additionally, the improper wetting of chitosan nanoparticles could lead to more filler-to-filler interactions than filler-to-matrix interactions and finally agglomeration of these nanoparticles ${ }^{(35)}$. Furthermore, this agglomeration may act as a point of stress concentration that could lead to nonuniform stress distribution ${ }^{(35,36)}$. When applying the load, the agglomeration restrains the movement of molecular deformation and reduces the fracture toughness ${ }^{(35)}$.

Phenomena of water uptake and loss is a property of the resin that could significantly affect the dimensional stability of the polymeric denture bases (37). The results of the present study revealed that the incorporation of chitosan nanoparticles into thermoplastic acrylic resin led to increasing water sorption and solubility of this resin respectively with the increase of amounts of incorporated nanoparticles. This can explain as the incorporation of these nanoparticles between the linear polymer chain of thermoplastic acrylic resin separate the polymer chains further apart from each other and increase spaces between the polymer chains ${ }^{(7,38)}$.

Furthermore, they can increase their porosity which leads to an increase in water sorption of thermoplastic resin. Other causes of porosities include air inclusion during the injection procedure ${ }^{(37,38)}$. Also, the increased solubility of thermoplastic resin may be due to their lower cross-linkage as its chemical structure mainly linear resin ${ }^{(38)}$.

\section{CONCLUSIONS}

The incorporation of chitosan nanoparticles into thermoplastic resin could adversely affect its flexural strength, impact strength, as well as fracture toughness. Also, the incorporation of these nanoparticles increases its water sorption and solubility. Moreover, the results of the present study revealed that; this deleterious effect of the incorporated chitosan nanoparticles increased with the increase of filler concentration. Thus the hypothesis was totally rejected.

\section{REFERENCES}

1. Song S-Y, Kim K-S, Lee J-Y, Shin S-W. Physical properties and color stability of injection-molded thermoplastic denture base resins. J Adv Prosthodont. 2019; 11:32-40

2. Abuelroos IM, Ibrahim TO, Elsisi HA, Makki AZ. The Effect of Different Packing Techniques on Adaptation of Resin Denture Base Materials. Int J Health Sci Res. 2020; 10:28-34.

3. Parvizi A, Lindquist T, Schneider R, Williamson D, Boyer D, Dawson DV. Comparison of the dimensional accuracy of injection-molded denture base materials to that of conventional pressure-pack acrylic resin. J Prosthodont. 2004;13: 83-89.

4. Kassem M, Saief-Elnasr M, Baraka Y, Helal MA. Bone Loss Evaluation for Kennedy Class I Partially Edentulous Patients with Acetal Resin Denture Base. EC Dental Science. 2020;19: 74-79.

5. Banu F, Jeyapalan K, Kumar AV, Modi K. Comparison of Colour Stability Between Various Denture Base Resins on Staining and Denture Cleansing Using Commercially Available Denture Cleansers. Cureus. 2020; 12: e6698- 73.

6. Yavuz T, Aykent F. Temporary Flexible Removable Partial Denture: A Clinical Report. Clinic Dentist Res. 2012; 36: 41-44.

7. Soesetijo FA, Prijatmoko D, Hidajati L. Biocompatibility of Thermoplastic Nylon Flexible Removable Partial Denture - A Review. Int J Curr Res Aca Rev. 2016; 4: 75-83.

8. DiTolla M. Valplast: Flexible, esthetic partial denture. Chairside Perspect. 2004;5: 1-4.

9. Shah J, Bulbule N, Kulkarni S, Shah R, Kakade D. Comparative evaluation of sorption, solubility, and microhardness of heat cure polymethylmethacrylate denture base resin and flexible denture base resin. J Clin Diagn Res. 2014;8: 1-4.

10. Biswas SK, Shams I, Das AK, Islam N, Nazhad MM. Flexible and Transparent Chitin/Acrylic Nanocomposite Films with High Mechanical Strength. Fiber Polym. 2015; 16: 774-81.

11. Sha B, Liu Q, Cheng L, Yin X. Preparation and Application of Core-shell PMMA/Chitosan Nanoparticle. Advance Mater Res. 2012; 535: 271-74.

12. Ergun G, Sahin Z, Ataol AS. The effects of adding various ratios of zirconium oxide nanoparticles to poly (methyl methacrylate) on physical and mechanical properties. J Oral Sci. 2018; 60: 304-15. 
13. Topouzi M, Kontonasaki E, Bikiaris D, Papadopoulou L, Paraskevopoulos KM, Koidis P. Reinforcement of a PMMA resin for interim fixed prostheses with silica nanoparticles. J Mech Behav Biomed Mater. 2017; 69, 213-22.

14. Gad M, ArRejaie AS, Abdel-Halim MS, Rahoma A. The reinforcement effect of nano-zirconia on the transverse strength of repaired acrylic denture base. Int J Dent. 2016;56-59.

15. Nam K-Y, Shin Y-M. Antifungal effect and characterization of denture PMMA impregnated with chitosan. Polym J. 2017; 44: 87-94.

16. Onishi H, Machida Y. Biodegradation and distribution of water-soluble chitosan in mice. Biomaterials. 1999; 20:175-82.

17. Wieckiewicz M, Boening KW, Grychowska N, Stolarz P. A Clinical application of chitosan in dental specialties. Mini Rev Med Chem. 2017; 17:401-09.

18. Wang B, Chen K, Jiang S, Reincke F, Tong W, Wang D, et al. Chitosan-mediated synthesis of gold nanoparticles on patterned poly(dimethylsiloxane) surfaces. Biomacromolecules. 2006; 7:1203-09.

19. American Dental Association Specification No.12 for denture base polymer. JADA. 1975; 90:451-58.

20. Koroglu A, Sahin O, Kurkcuoglu I, Dede DO, Osdemlr T, Hazer B. Silver nanoparticle incorporation effect on mechanical and thermal properties of denture base acrylic resins. J Appl Oral Sci. 2016; 24:590-6.

21. British Standard Institute Specification No.771 for acrylic denture base materials BS. Institution London 1984.

22. Begum SS, Ajay R, Devaki V, Divya K, Balu K, Kumar PA. Impact strength and dimensional accuracy of heat-cure denture base resin reinforced with $\mathrm{ZrO} 2$ nanoparticles: An in vitro study. J Pharm BioAllied Sci. 2019; 11:365-70.

23. Ahmed MA, Ebrahim MI. Effect of Zirconium Oxide Nano-Fillers Addition on the Flexural Strength, Fracture Toughness, and Hardness of Heat- Polymerized Acrylic Resin. World J Nano Sci and Eng. 2014;4: 50-57.

24. 24- International Organization for Standardization. Specification 1567: denture base polymer. 2nd ed. Switzerland: (ISO); 1996.

25. Sahin Z, Gulfem Ergun G. The Assessment of Some Physical and Mechanical Properties of PMMA Added Different Forms of Nano-ZrO2. J Dent Oral Health. 2017; 3:64-73.

26. Zirak M, Vojdani M, Mohammadi S, Khaledi AA. Com- parison of the water sorption and solubility of four reline acrylic resins after immersion in food-simulating agents. $J$ Int Soc Prevent Communit Dent. 2019; 9:40-46.

27. Nguyen LG, Kopperud HM, Øilo M. Water sorption and solubility of polyamide denture base materials. Acta Biomaterialia Odontologica Scandinavica. 2017; 3: 47-52.

28. Bhargava A, Nagpal A, Kumar M, Bhargav R. Flexible dentures demystified. Dental Technician. 2010; 2:18- 21.

29. Shi JM, Bao YZ, Huang ZM, Weng ZX. Preparation of Poly (Methyl Methacrylate)/Nanometer Calcium Carbonate Composite by in Situ Emulsion Polymerization. J Zhejiang Uni Sci. 2004; A: 709-13.

30. Yunus N, Rashid AA, Azmi LL, Abu-Hassan MI. Some flexural properties of a nylon denture base polymer. J Oral Rehabil. 2005; 32: 65-71.

31. Radzi Z, AbuKasim NH, Yahya NA. Impact strength of an experimental polyurethane-based polymer. Annal Dent Univ Malaya. 2007; 14:46-51.

32. Petterson RW, Bodig J. Prediction of fracture toughness of conifers. Wood Fib Sci. 2007; 15: 302-07.

33. Andreotti AM, Goiato MC, Moreno A, Nobrega AS, Pesqueira AA, dos Santos DM. Influence of Nanoparticles on Color Stability, Microhardness, and Flexural Strength of Acrylic Resins Specific for Ocular Prosthesis. Int J Nanomedicine. 2014; 9: 5779-87.

34. Kundie F. Azhari CH, Muchtar A, Ahmad ZA. Effects of filler size on the mechanical properties of polymer-filled dental composites: A review of recent developments. J Phys Sci. 2018;29: 141-65.

35. Kundie F, Azhari CH, Ahmad ZA. Effect of nano-and micro-alumina fillers on some properties of poly (methyl methacrylate) denture base composites. J Serb Chem Soc. 2018; 83: 75-91.

36. Gad MM, Fouda SM, Al-Harbi F, Näpänkangas R, Raustia A, Al-Harbi F. PMMA denture base material enhancement: A review of fiber, filler, and nanofiller addition. Int J Nanomed. 2017; 12:3801-12.

37. Wiedemair V, Wolfgang Huck C. Monitoring water absorption of medically used PMMA using NIR. NIR news. $2017 ; 28: 10-13$.

38. Takahashi Y, Hamanaka I, Shimizu H. Effect of thermal shock on mechanical properties of injection-molded thermoplastic denture base resins. Acta Odontol Scand. 2012; 70: 297-02. 